\title{
Phytochemicals and antioxidant capacity of wild growing and in vitro Hypericum heterophyllum
}

\author{
CENNET YAMAN ${ }^{*}$
}

${ }^{1}$ Department of Field Crops, Faculty of Agriculture, Bozok University, Yozgat, Turkey

\begin{abstract}
In vitro cultures of Hypericum heterophyllum Vent. was established by using MS and MS-B5 medium contained plant growth regulators such as kinetin, BAP, IAA, TDZ and picloram. Flower, leaf, stem and in vitro samples (callus and in vitro plantlets) of $H$. heterophyllum were analysed by LC-MS/MS for their chemical contents such as quinic acid, gallic acid, (+)-catechin, ferulic acid, vanillic acid, $p$-coumaric acid, caffeic acid, and quercetin; moreover their radical scavening activities conducted by DPPH and ABTS methods were evaluated. Among all the analysed samples, the in vitro plantlets shown the highest antioxidant activity ( $\mathrm{IC}_{50}, 220 \mu \mathrm{g} / \mathrm{mL}$ for DPPH and $254 \mu \mathrm{g} / \mathrm{mL}$ for ABTS), probably due to the presence of phenolic acids and flavonoids, specifically the higher total phenolic content $(64.4 \mathrm{mg} \mathrm{GAE} / \mathrm{g}$ extract) than other samples. The phytochemical variation among all samples was discussed through principal component analysis (PCA) and hierarchical cluster analysis (HCA). The in vitro plantlets might offer possibilities for the production of high-value secondary metabolites as pharmaceuticals and food preservatives. This study is the first report on analyses and comparison of secondary metabolites and antioxidant activities in different plant parts and in vitro samples of endemic $H$. heterophyllum.
\end{abstract}

Keywords Hypericum, in vitro plantlets, antioxidant activity, phytochemical.

To cite this article: YAMAN C. Phytochemicals and antioxidant capacity of wild growing and in vitro Hypericum heterophyllum. Rom Biotechnol Lett. 2020; 25(6): 2111-2117. DOI: $10.25083 / \mathrm{rbl} / 25.6 / 2111.2117$

$\square$ *Corresponding author: CENNET YAMAN, Department of Field Crops, Faculty of Agriculture, Bozok University, Yozgat, Turkey; Tel: +90 (0354) 24210 28/4469; Fax: +90 (0354) 2421096

E-mail: cennet.yaman@bozok.edu.tr 


\section{Introduction}

Hypericum genus belonging to the Hypericaceae (previously Clusiaceae or Guttiferae) family contains a wide variety of secondary metabolites known as mainly napthodianthrones (hypericin, pseudohypericin, protohypericin), flavonoids (campherol, quercetin, rutin, luteolin, hyperin, hyperoside), phenolic acid (chlorogenic acid), phloroglucinols (hyperforin, furohyperforin), xanthones and essential oils (Z.A.T FOBOFOU \& al [1]). These components exhibit very important biological activities such as antioxidant, antidepressant, antitumor, antibacterial, antimicrobial, anti-inflammatory effects and others (C. ZORZETTO \& al [2]).

At the present time, the most well-known member of this genus, Hypericum perforatum (St. John's wort), a rich source for flavonoids, widely consumed for medicinal purpose in all over the world. However, only a relatively few of them have been investigated in terms of their phytochemical content and biological/pharmacological activity, therefore, a large majority (about 60\%) of the Hypericum species in need of attention due to their medicinal value (S.L. CROCKETT \& al [3]). One of these species is Hypericum heterophyllum in which very few studies on chemical components such as essential oil content and its hypericin/pseudohypericin contents and biological activities of the species such as antioxidant and antimicrobial (A.K. AYAN \& al [4]; E.L. UNAL \& al [5]) were reported upto date. A.K. AYAN \& al [4] stated that the aerial parts (flower, leaf and stem) of the species contain no hypericin and pseudohypericin.

Establishing in vitro cultures is a great tool for the production of desirable secondary metabolites under a controlled environment, independent of seasonal and geographical conditions. In previous studies, significant secondary metabolite production such as total phenols, flavonoids, hyperoside, hypericin, pseudohypericin and others were obtained specially from shoot, root, hair, callus and suspension culture of $H$. perforatum were reported (O. TUSEVSKI \& al [6]; K. NIGUTOVÁ \& al [7]). But, there are no reports about in vitro production of secondary metabolite production and analysed for $H$. heterophyllum, to this point.

The aim of the present study was to investigate endemic $H$. heterophyllum in terms of (1) production of undifferentiated callus and shoot culture; (2) content of eight secondary metabolites, such as gallic acid, quinic acid, quercetin, vanillic acid, (+)-catechin, $p$-coumaric acid, caffeic acid, ferulic acid, in different parts of the wild-growing plant and in vitro samples for the first time by LC-MS/MS; (3) characterization and comparison of the callus, in vitro plantlets, the plant parts extracts with respect to their to determine total phenolic and flavonoid contents, moreover antioxidant properties using DPPH and ABTS radicals; (4) examination whether or not there is a relationship between the samples of the plant by using principal component analysis, multiple comparison test, and cluster analysis.

\section{Materials and Methods}

\section{Plant material}

The aerial parts of wild growing $H$. heterophyllum Vent. representing a total of 40 shoots were collected at full flowering period between 11:00 a.m. and 13:00 p.m. from Yozgat/Turkey $\left(39^{\circ} 46^{\prime} \mathrm{N}, 34^{\circ} 47^{\prime} \mathrm{E}, 1332 \mathrm{~m}\right)$. The species was identified, and the herbarium specimen was deposited in a herbarium (voucher number: 28281) placed in Selcuk University. The seeds of $H$. heterophyllum were handpicked from 30 randomly selected Hypericum plants and stored at $4 \pm 2{ }^{\circ} \mathrm{C}$ in sealed plastic bags until used for in vitro cultures.

\section{Source of explants for in vitro cultures}

The seeds of $H$. heterophyllum were surface sterilized by treatment by immersion in $20 \%$ sodium hypochlorite for $20 \mathrm{~min}$, and followed by 3-4 times rinses in sterile distilled water. After sterilization, the seeds were germinated on the Murashige and Skoog (MS) basal media containing $2 \mathrm{mg} / \mathrm{L}$ $\mathrm{GA}_{3}$ (gibberellic acid), 30\% (w/v) sucrose and $0.7 \%(\mathrm{w} / \mathrm{v})$ agar. Twenty five seeds were cultured in each petri dishes and incubated in a growth chamber under photoperiod of $16 \mathrm{~h}$ at $24 \pm 1^{\circ} \mathrm{C}$. Two week-old seedlings served as the source for further explants.

\section{Shoot production}

The nodal segments were cultured on MS medium supplemented with three different types of plant growth regulators (PGRs) $(0.25 \mathrm{mg} / \mathrm{L}$ BAP (6-benzylaminopurine), $1.0 \mathrm{mg} / \mathrm{L}$ IAA (indole-3-acetic acid) and $0.5 \mathrm{mg} / \mathrm{L}$ kinetin). The explants were subcultured at the end of the two weeks and after two months of culture, secondary metabolite contents and antioxidant activities consisting of shoot were determined.

\section{Callus production}

Nodal segments of $H$. heterophyllum were placed on MS-B5 (medium supplemented with $1.0 \mathrm{mg} / \mathrm{L}$ TDZ (thidiazuron) and $0.10 \mathrm{mg} / \mathrm{L}$ picloram. The explants were subcultured every two weeks, 45 day old callus cultures were analysed.

\section{Extraction}

The aerial parts (flower, leaf and stem) of the wildgrowing $H$. heterophyllum and in vitro samples (callus and in vitro plantlet) were used for the extraction. The aerial parts were dried under shade and mechanically ground with a blender while callus was ground with a mortar and pastle in a liquid nitrogen. $4 \mathrm{~g}$ (three replicate) of each grounded plant materials were extracted individually in $40 \mathrm{ml}$ of $100 \%$ methanol at $40^{\circ} \mathrm{C}$ for $24 \mathrm{~h}$. The resulting solutions were filtered through whatman paper and the solvent was removed on a rotary evaporator at temperature bellow $40^{\circ} \mathrm{C}$. Extract yields of flower, leaf and stem, in vitro plantlet, callus were recorded $16.6 \%, 19.8 \%, 16.9 \%$, $11.0 \%, 3.4 \%$, respectively. 


\section{Total phenolic content (TPC)}

The total phenolic content was analysed according to the Folin-Ciocalteu reagent (FCR) by the methodology of V.L. SINGLETON \& al [8] with a slight modification. For the analysis, $200 \mu \mathrm{L}$ extract was mixed with $9.0 \mathrm{ml}$ distilled water, and added $200 \mu \mathrm{L}$ FCR. After shaken vigorously for $3 \mathrm{~min}, 600 \mu \mathrm{l}$ of a $20 \% \mathrm{Na}_{2} \mathrm{CO}_{3}$ solution was added to the mixture. The total phenol content was calculated at $760 \mathrm{~nm}$ after the incubation in dark at room temperature for $2 \mathrm{~h}$. The results were expressed as $\mathrm{mg}$ equivalents of gallic acid (GAE) per gram of extract according to the equation obtained from the standard gallic acid graph $\left(\mathrm{y}=0.0089 \mathrm{x}-0.0003, \mathrm{R}^{2}=0.999\right)$.

\section{Total flavonoid content (TFC)}

Total flavonoid contents were determined according to A. ARVOUET-GRAND \& al [9]. In brief, $200 \mu \mathrm{L}$ extract was mixed with $100 \mu \mathrm{L}$ of a $10 \%$ aluminium nitrate and $100 \mu \mathrm{L}$ of a $1.0 \mathrm{M}$ potassium acetate. Total volume of the solution was adjusted $4.0 \mathrm{~mL}$ with ethanol. Absorbance measurements were recorded at $417 \mathrm{~nm}$ after $40 \mathrm{~min}$ incubation at room temperature in dark. Total flavonoid contents were expressed as mg equivalents of quercetin (QE) per gram of extract according to the equation obtained from the standard quercetin graph $(\mathrm{y}=0.0122 \mathrm{x}+$ $\left.0.065, \mathrm{R}^{2}=0.998\right)$.

\section{Liquid chromatography coupled with tandem mass spectrometry (LC-MS/MS) analysis and identification}

Quantitative analysis of compounds was performed by LC-MS/MS, Thermo Scientific - Dionex Ultimate 3000 TSQ Quantum with Thermo ODS Hypersil $250 \times 4.6 \mathrm{~mm}$, $5 \mu \mathrm{m}$ column. The injection volume was $10 \mu \mathrm{L}$. The mobile phase included eluent water with $0.1 \%$ formic acid (A) and methanol (B). The flow rate was $0.7 \mathrm{~mL} / \mathrm{min}$, and the column temperature was set to $40^{\circ} \mathrm{C}$. The gradient programme was fixed as follow: $0-5 \mathrm{~min}, 100 \% \mathrm{~A}$,
5-20 $\min , 95 \%$ A, 20-20.1 $\mathrm{min}, 20 \%$ A, 20.1-26 min, $5 \%$ A, 26-30 min 100\% B. Total process time was $30 \mathrm{~min}$. The injection volume was $10 \mu \mathrm{L}$. Method Validation parameters of compounds are also shown in Table 1.

The analytical method was validated to determine the linearity, limits of detection (LODs), limits of quantification (LOQs) and precision. The relationship between peak area and concentration was linear from 50 to $100 \mu \mathrm{g} / \mathrm{mL}$ (ppb) for each compound. Linearity was assessed using linear regression analysis of six points for each compound. Linear plot consists of triplicate per point. The correlation coefficients $\left(R^{2}\right.$ values) were found to be $\geq 0.99$. Linear regression equations of the compounds are also reported in Table 1. LOD and LOQ were determined by using measurements of reagent blanks spiked with low concentrations of analyte according to Eurachem Guide (Laboratory Guide to Method Validation and Related Topics, 2014). The blanks solution was spiked to $5 \mathrm{ppb}$ standard. Calculate LOD and LOQ as LOD $=3 \times \mathrm{S}_{0}$ and LOQ $=10 \times \mathrm{S}_{0}$. The repeatability in the intra-day values (relative standard deviation, RSD\%) for compounds, using the corresponding peak areas of three replicate analyses at all the concentration levels. The trueness was examined as recovery of each compound from mixed stock standard solutions in spiked plant extracts. The recovery was evaluated by means of three replicate measurements in a day. The average recovery data of the compounds were determined using the following formula:

$$
\text { Recovery }(100 \%)=\left(\frac{\text { Measured concentration }}{\text { Spiked concentration }}\right) \times 100
$$

The concentration of compounds in samples of the plant was obtained from either one of the corresponding calibration curves. Finally, each bioactive amount for each samples were calculated mg/100 g DW (A. SHRIVASTAVA \& al [10]).

Table 1. Linear regression equation and correlation coefficient, precision of each detected compounds by LC-MS/MS analysis on Hypericum heterophyllum

\begin{tabular}{ccccccc}
\hline $\begin{array}{c}\text { Composition } \\
(\boldsymbol{\mu} \mathbf{g} / \mathbf{g})\end{array}$ & Linear regression equation & $\boldsymbol{R}^{\mathbf{2}}$ & $\begin{array}{c}\text { LOD } \\
(\boldsymbol{\mu g} / \mathbf{L})\end{array}$ & $\begin{array}{c}\text { LOQ } \\
(\boldsymbol{\mu} \mathbf{g} / \mathbf{L})\end{array}$ & $\begin{array}{c}\text { RSD } \\
(\boldsymbol{\%})\end{array}$ & $\begin{array}{c}\text { Recovery } \\
(\boldsymbol{\%})\end{array}$ \\
\hline Quinic acid & $\mathrm{y}=483.60 \times-10563$ & 0,999 & 5.52 & 6.92 & 4.07 & 97.75 \\
Gallic acid & $\mathrm{y}=464.58 \times-10423$ & 0.999 & 5.38 & 6.78 & 4.45 & 96.45 \\
Vanillic acid & $\mathrm{y}=603.27 \times-19881$ & 0.997 & 4.99 & 6.11 & 4.12 & 101.25 \\
Caffeic acid & $\mathrm{y}=1219.67 \times-7914$ & 0.999 & 5.45 & 7.13 & 2.74 & 98.55 \\
$p$ - coumaric acid & $\mathrm{y}=4773.03 \times+86775$ & 0.996 & 7.33 & 11.11 & 3.14 & 99.85 \\
Ferulic acid & $\mathrm{y}=322.29 \times-4272$ & 0.998 & 6.62 & 9.00 & 4.90 & 100.15 \\
(+)-catechin & $\mathrm{y}=598.80 \times+882$ & 0.997 & 5.12 & 6.31 & 2.85 & 99.14 \\
Quercetin & $\mathrm{y}=18760 \times-131657$ & 0.998 & 6.62 & 11.59 & 2.21 & 99.90 \\
\hline
\end{tabular}

$R^{2}$ - regression coefficient, LOD - limit of detection, LOQ - limit of quantification, RSD - relative standard deviation

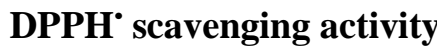

Radical scavenging activity of the extracts was determined using the DPPH radical (M.S. BLOIS [11]) Briefly, $200 \mu \mathrm{L}$ of methanolic solution of all tested extracts at five different concentrations was mixed with
$3.2 \mathrm{~mL}$ of a $0.004 \%$ solution of $\mathrm{DPPH}^{*}$ in $100 \%$ methanol. Ascorbic acid (AA) and trolox as standard were used. After a $30 \mathrm{~min}$ incubation at room temperature in dark, absorbance of the sample was measured at $517 \mathrm{~nm}$. 


\section{$\mathrm{ABTS}^{\cdot+}$ scavenging activity}

ABTS was used for evaluation of radical cation scavenging activity according to the method described by R. RE \& al [12]. The absorbances were recorded at $734 \mathrm{~nm}$ after a $30 \mathrm{~min}$ incubation at room temperature in the dark. AA and trolox as standard were used.

\section{Statistical analysis}

All data was statistically analysed using one-way ANOVA, and comparison of the means was carried out by Duncan's multiple range tests at a significance level of 0.01 and the data were given as the mean \pm standard error. The data matrix of the plant samples was obtained from various statistical evaluations, including principal component analysis (PCA) and hierarchical cluster analysis (HCA).

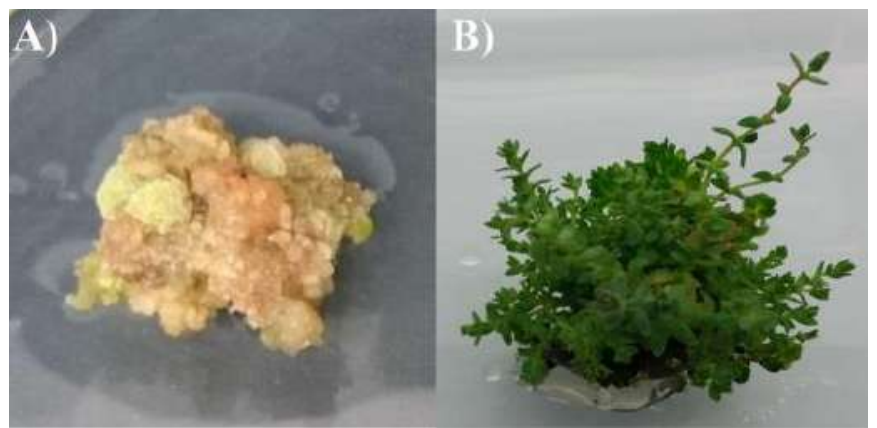

Figure 1. In vitro samples of Hypericum heterophyllum. A) Callus formation from nodal segments cultivated on MS-B5 + $1.0 \mathrm{mg} / \mathrm{L}$ $\mathrm{TDZ}+1.0 \mathrm{mg} / \mathrm{L}$ picloram. B) Shoot induction from nodal segments cultivated on $\mathrm{MS}+0.25 \mathrm{mg} / \mathrm{L} \mathrm{BAP}+0.5 \mathrm{mg} / \mathrm{L}$ kinetin $+1.0 \mathrm{mg} / \mathrm{L}$ IAA.

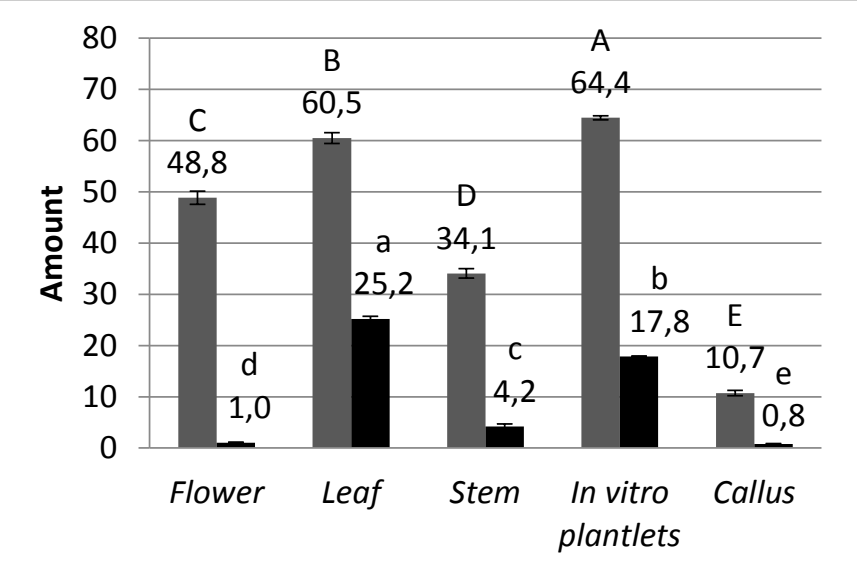

Different parts of Hypericum heterophyllum

$$
\text { -TPC (mg GAE/g extract) } \quad \text {-TFC ( mg QE/g extract) }
$$

Figure 2. Total phenolic and flavonoid contents in flower, leaf, stem, in vitro plantlet, callus of Hypericum heterophyllum. Big letters for TPC and small letters for TFC and on the columns indicate Duncan at $P<0.01$.

\section{Results and Discussion}

\section{Callus and shoot induction}

Callus formation was determinated in the MS-B5 medium supplemented with $1.0 \mathrm{mg} / \mathrm{L} \mathrm{TDZ}$ and $0.10 \mathrm{mg} / \mathrm{L}$ picloram. The calli were yellowish in color and fragile (Fig. 1A). Also, callus development was observed to be slow and poor. Many researchers notified that induction and growth of callus of Hypericum species were slow and compact (A.K AYAN \& al [13]; S.A KHAN \& al [14]). But, Kinetin and BAP has been found favourable for multiplication of some Hypericum species in vitro shoots (A.K AYAN \& al [13]; H. SOOD \& al [15]; I. BĂCILĂ \& al [16]). We found that Kinetin and BAP were very effective on shoot induction from nodal segments of H. heterophyllum (Fig. 1B).

\section{Total phenolic content (TPC) and total flavonoid content (TFC)}

The total quantity of TPC and TFC were recorded in Fig. 2, and found statistically significant differences $(p<0.01)$. The highest TPC was determined in vitro plantlets cultivated in media containing $0.25 \mathrm{mg} / \mathrm{L}$ BAP, $1.0 \mathrm{mg} / \mathrm{L}$, IAA and $0.5 \mathrm{mg} / \mathrm{L}$ kinetin, and this media was found to be very effective for increasing TPC in $H$. heterophyllum. X.H. CUI \& al [17] reported that combination of IBA (indole-3-butyric acid) and IAA was more effective than NAA (1-naphthaleneacetic acid), moreover, kinetin was better than BAP and TDZ for increasing phenolic contents in a different Hypericum species. On the other hand, the level of TPC and TFC in the callus culture cultivated in MS-B5 media supplemented with $1.0 \mathrm{mg} / \mathrm{L} \mathrm{TDZ}$ and $0.10 \mathrm{mg} / \mathrm{L}$ picloram demonstrated the lowest among the other samples. Similarly to this study, V. KUMAR \& al [18] stated that combination effect of picrolam (different concentrations) and $1.0 \mathrm{mg} / \mathrm{L}$ TDZ on TPC in callus of Pelargonium sidoides was exhibited a very strong negative effect compared to control and other concentration of TDZ. K. DANOVA \& al [19] reported that MS medium was the most effective for production of flavonoids than B5 medium. Therefore, these results may attributed to the PGRs or the excess number of the leaves of the in vitro plantlets (Fig. 1B). Because, among all the samples, the leaf had the highest TFC, and followed by the in vitro plantlets.

\section{Phytochemicals of Hypericum heterophyllum}

The amounts of the identified phytochemicals by LC-MS/MS in methanolic extracts of flower, leaf, stem, in vitro plantlets and callus of $H$. heterophyllum is presented in Table 2. 
Table 2. Phytochemicals in flower, leaf, stem, in vitro plantlet, callus of Hypericum heterophyllum $(\mathrm{mg} / 100 \mathrm{~g} \mathrm{DW})$

\begin{tabular}{lccccc}
\hline Compounds & Flower & Leaf & Stem & In vitro plantlet & Callus \\
\hline Quinic acid & $38.7 \mathrm{c}$ & $145.4 \mathrm{a}$ & $58.1 \mathrm{~b}$ & $6.6 \mathrm{~d}$ & $0.2 \mathrm{e}$ \\
Gallic acid & $0.46 \mathrm{~b}$ & $1.90 \mathrm{a}$ & $0.44 \mathrm{~b}$ & $0.53 \mathrm{~b}$ & $0.08 \mathrm{c}$ \\
Vanillic acid & $1.09 \mathrm{c}$ & $1.45 \mathrm{~b}$ & $1.05 \mathrm{c}$ & $2.14 \mathrm{a}$ & $0.05 \mathrm{~d}$ \\
Caffeic acid & $1.55 \mathrm{a}$ & $1.17 \mathrm{~b}$ & $0.45 \mathrm{~d}$ & $0.68 \mathrm{c}$ & $0.01 \mathrm{e}$ \\
-coumaric acid & $0.13 \mathrm{~b}$ & $0.03 \mathrm{c}$ & $0.01 \mathrm{~d}$ & $0.21 \mathrm{a}$ & $0.0 \mathrm{~d}$ \\
Ferulic acid & $0.58 \mathrm{~b}$ & $0.44 \mathrm{c}$ & $0.22 \mathrm{e}$ & $1.72 \mathrm{a}$ & $0.33 \mathrm{~d}$ \\
(+)- catechin & $0.09 \mathrm{~d}$ & $0.24 \mathrm{c}$ & $2.46 \mathrm{~b}$ & $6.59 \mathrm{a}$ & $0.02 \mathrm{e}$ \\
Quercetin & $9.03 \mathrm{~b}$ & $3.18 \mathrm{c}$ & $9.65 \mathrm{a}$ & $0.87 \mathrm{~d}$ & $0.02 \mathrm{e}$ \\
\hline
\end{tabular}

Statistically. each column was evaluated separately and indicated in small letters $(P<0.01)$

Among all the samples, generally lower amount of the compounds were recorded in the callus. In comparison of the compounds tested, quinic acid was found in all samples as a major product except callus that contained the highest amount of ferulic acid $(0.33 \mathrm{mg} / 100 \mathrm{~g}$ DW $)$ among other compounds. Caffeic acid was found the highest amount with $1.55 \mathrm{mg} / 100 \mathrm{~g} \mathrm{DW}$ in the flower. The stem consisted of the highest quercetin level $(9.65 \mathrm{mg} / 100 \mathrm{~g} \mathrm{DW})$ among all samples.

PCA was applied to the data matrix of chemical contents ( 8 chemical $\times 5$ cases) of the in vitro samples and different parts of $H$. heterophyllum growing wild. The principal components, which have eigenvalues higher than 1 were extracted. This led to the formation of two principal components. The PC1 accounted for $44.26 \%$, the PC2 for $33.67 \%$ of the total variation of all chemical data. The chemical components were rotated using Varimax rotation. Fig. 3 shows the two-way score and loading plots for PC1 and PC2. Fig. 3B shows a cluster of chemical components with large positive loadings on PC1. It includes $p$-coumaric, vanillic acid, ferulic acid, and (+)-catechin. It can be commented from the loading and score plots for PC1-PC2 (Fig. 3A and B) that (+)-catechin, vanillic acid, $p$-coumaric and ferulic acid concentrations are higher for the in vitro plantlets $(6.59,2.14,0.21$ and $1.72 \mathrm{mg} / 100 \mathrm{~g} \mathrm{DW}$, respectively). In addition, quinic acid and gallic acid had the highest value on PC1. This can be interpreted from PC1 and PC2 that quinic acid (144.11 mg/100 g DW) and gallic acid $(1.98 \mathrm{mg} / 100 \mathrm{~g} \mathrm{DW})$ concentrations are highest for the leaf.

A hierarchical clustering by applying the Betweengroups linkage method, which uses the squared Euclidean distance as a similarity measure, was applied using the SPSS package. In dendrogram, according to the phytochemical compounds tested, the flower and stem were in the same group, and the leaf was in the group close to them while the in vitro plantlets alone formed a separate entity from other samples (Fig. 4). The callus was in the group close to the in vitro plantlets. The parallelism between the distribution of PCA and the dendrogram suggests an appreciable degree of congruence between the two.

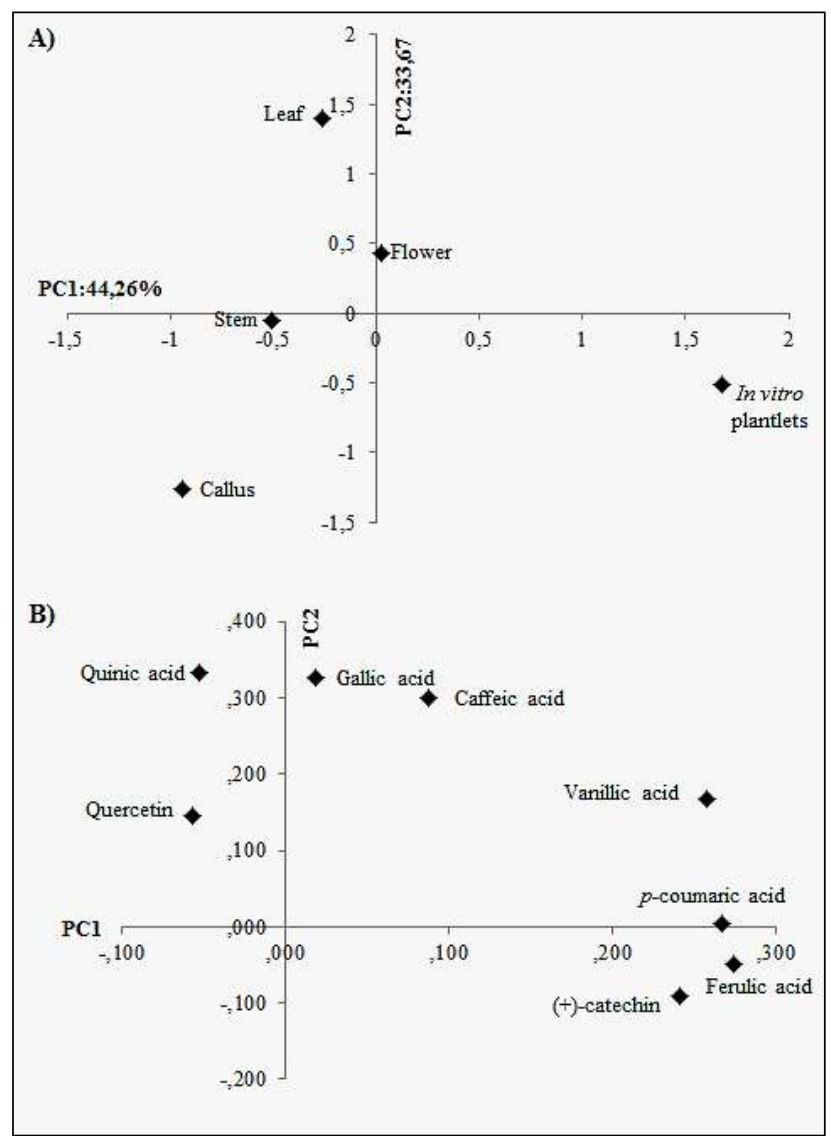

Figure 3. The score (A) and loading (B) plots for phytochemical contents of $H$. heterophyllum.

In this study, we found that ferulic acid, p-coumaric, vanillic acid, and (+)-catechin among the compounds tested for $H$. heterophyllum could be produced much more than those in different parts of the plant growing wild by in vitro culture. The in vitro plantlets synthesized 2 times more $(+)$-catechin than the stem that contained the highest (+)-catechin among different parts of $\mathrm{H}$. heterophyllum growing wild. Also, the amount of $p$-coumaric acid in the in vitro plantlets was found about 2 times higher than in the flowers, 7 times abundant than in the leaf, 21 times more than in the stem samples. 
The amount of vanillic acid of the in vitro plantlets was about 2 times increase as compared to the plant parts. Vanillic acid, a dihydroxybenzoic acid derivative has very weak antioxidant activity, but used widely as a fragrance, flavoring and food preserving agent. The price has increased about 20-fold between 2012 and 2018 for this compound, which has a global market in several areas. In this way, it opened the route to alternative vanillin production methods R. CIRIMINNA \& al [20]. One of these alternative productions, vanillic acid, is synthesized from ferulic acid as natural product, and the price of this biotechnological vanillic acid is also considerably high R. DELISI \& al [21]. The in vitro plantlets was notable for the presence of high amounts of ferulic acid, and found about 4 times more abundant than in the flower and leaf, 8 times more abundant than in the stem.

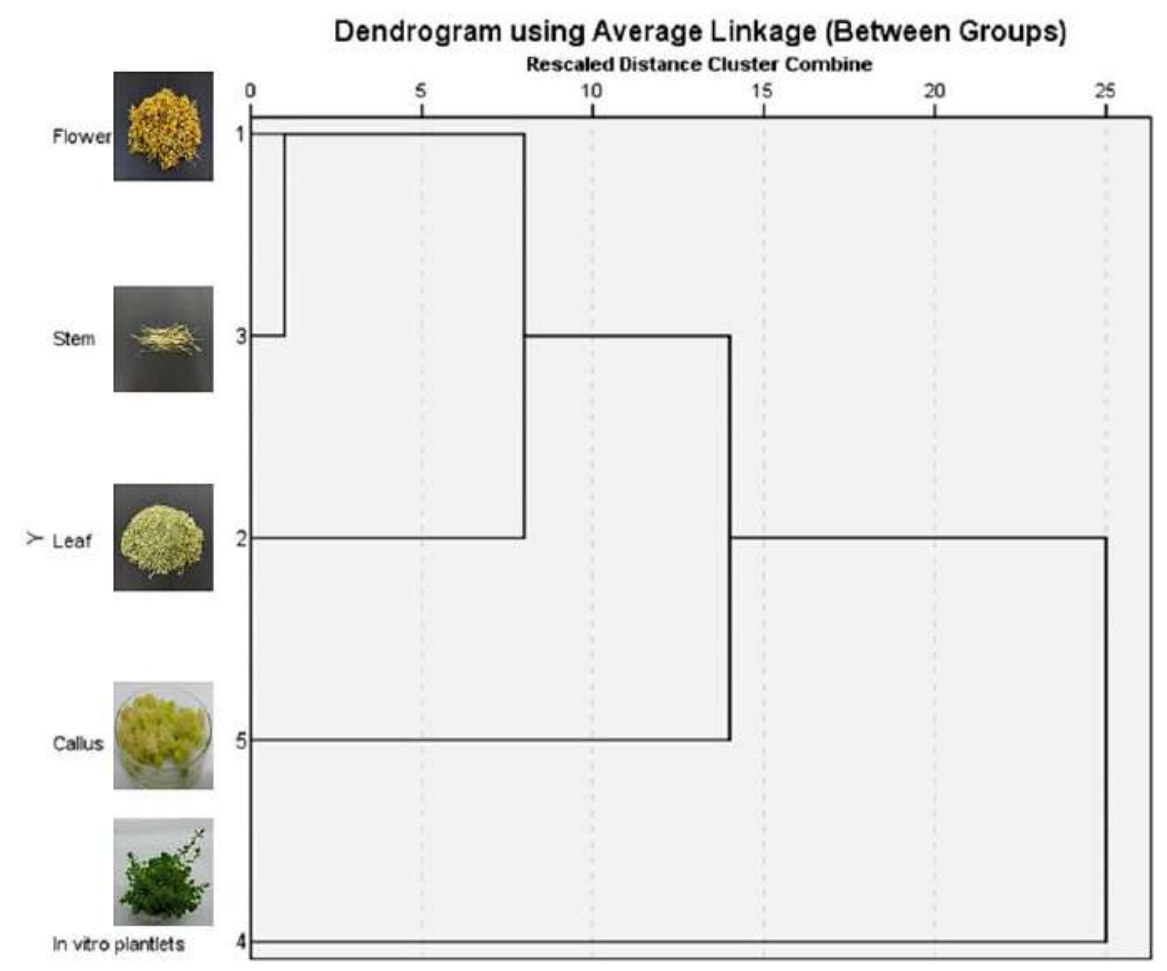

Figure 4. Dendrogram of $H$. heterophyllum samples (versus each of the eight metabolites under study) obtained by hierarchical cluster analysis using square Euclidean distance.

\section{The radical scavenging activity}

In this study, the radical scavenging activity of all samples of $H$. heterophyllum growing wild and in vitro samples was evaluated by means of the DPPH and ABTS assays, and expressed as $\mathrm{IC}_{50}$ values (Table 3 ). The results were compared with those of trolox and ascorbic acid (AA) used as standard.

Table 3. Free radical scavenging activities of flower, leaf, stem, in vitro plantlet, callus of Hypericum heterophyllum ( $\mathrm{IC}_{50}$ values)

\begin{tabular}{lrrr}
\hline Samples & DPPH & \multicolumn{1}{c}{ ABTS } \\
\hline Flower & $800 \pm 3.1$ & $\mathrm{e}$ & $782 \pm 1.7$ \\
Leaf & $342 \pm 1.0 \mathrm{c}$ & $420 \pm 0.3 \mathrm{~d}$ \\
Stem & $544 \pm 3.4 \mathrm{~d}$ & $690 \pm 1.2 \mathrm{e}$ \\
In vitro plantlets & $220 \pm 0.4 \mathrm{~b}$ & $255 \pm 0.9 \mathrm{c}$ \\
Callus & $1457 \pm 10.4 \mathrm{f}$ & $8863 \pm 1.6 \mathrm{~g}$ \\
Trolox & $109 \pm 1.3 \mathrm{a}$ & $101 \pm 0.2 \mathrm{~b}$ \\
AA & $59 \pm 0.0 \mathrm{a}$ & $56 \pm 1.9 \mathrm{a}$ \\
\hline
\end{tabular}

Statistically. each column was evaluated separately and indicated in small letters $(P<0.01)$

The in vitro plantlets with $\mathrm{IC}_{50}, 254.95 \pm 0.9 \mu \mathrm{g} / \mathrm{mL}$ for ABTS and $220.14 \pm 0.4 \mu \mathrm{g} / \mathrm{mL}$ for DPPH showed the stronger activity in both assays, which was significantly lower than that of standards such as ascorbic acid $(55.68 \pm 1.9 \mu \mathrm{g} / \mathrm{mL}$ and $59.06 \pm 0.1 \mu \mathrm{g} / \mathrm{mL}$, respectively) and trolox (100.66 \pm 0.2 and $108.88 \pm 0.13 \mu \mathrm{g} / \mathrm{mL}$, respectively). For both activities, the in vitro plantlets demostrated the strongest activity, followed by the leaf, stem, flower and callus. Similarly, among the aerial parts of $H$. perforatum L., the leaf shown the higher DPPH activity than other parts 
of the plant, and the lower than AA as a standard N. SEKEROGLU \& al [22]. In previous studies, similar to results were reported that many Hypericum species displayed the lower antioxidant activity than the standards C. Zorzetto \& al [2]. The variations of antioxidant activity in $\mathrm{H}$. heterophyllum samples may be attributed to differences and amounts of chemical compounds in the samples. Because, the callus that contained lowest TPF and TFC exhibited the lowest antioxidant activity.

\section{Conclusion}

This study provides novel information about phytochemical compositions, total phenolics, flavonoids and radical scavenging activities of $H$. heterophyllum. Furthermore, statistical analysis of PCA and HCA for the phytochemicals of the plant was conducted for the first time. Among the samples, the in vitro plantlets on MS medium supplemented with BAP, IAA and kinetin was very effective for the productions of ferulic acid, vanillic acid, (+)-catechin and $p$-coumaric acid. Consequently, statistical analyses have demonstrated that these compounds could be synthesized and accumulated more in vitro cultures than that in different parts of $H$. heterophyllum growing-wild. The in vitro production of these compounds used for many purposes may be very important. Especially, in vitro production of ferulic acid and vanillic acid may be considered to be important for the natural production of vanillin. Conclusively, further studies are necessary to exploit the biosynthetic potential, different extraction methods and to reveal production of other specific bioactive metabolites of $H$. heterophyllum.

\section{Acknowledgement}

Author would express their deep thanks for Dr. Ufuk KOCA-CALISKAN, Gazi University, Turkey for technical support during interpretation of data.

\section{References}

1. FOBOFOU SAT, FRANKE K, SANNA G, PORZEL A et al. Isolation and anticancer, anthelminthic, and antiviral (HIV) activity of acylphloroglucinols, and regioselective synthesis of empetrifranzinans from Hypericum roeperianum. Bioorg Med Chem. 2015; 23: 6327-6334.

2. ZORZETTO C, SÁNCHEZ-MATEO CC, RABANAL $\mathrm{RM}$, LUPIDI $\mathrm{G}$ et al. Phytochemical analysis and in vitro biological activity of three Hypericum species from the Canary Islands (Hypericum reflexum, Hypericum canariense and Hypericum grandifolium). Fitoterapia. 2015; 100: 95-109.

3. CROCKETT SL, ROBSON NKB. Taxonomy and chemotaxonomy of the genus Hypericum. Med Aromat Plant Sci Biotechnol. 2011; 5: 1-13.

4. AYAN AK, ÇIRAK C. Hypericin and pseudohypericin contents in some Hypericum Species growing in Turkey. Pharm Biol. 2008; 46: 288-291.

5. UNAL EL, MAVI A, KARA AA, CAKIR A et al. Antimicrobial and antioxidant activities of some plants used as remedies in Turkish traditional medicine. Pharm Biol. 2008; 46: 207-224.

6. TUSEVSKI O, STANOEVA JP, MARKOSKA E, BRNDEVSKA $\mathrm{N}$ et al. Callus cultures of Hypericum perforatum L. a novel and efficient source for xanthone production. PCTOC. 2016; 125: 309-319.

7. NIGUTOVÁ K, KUSARI S, SEZGIN S, PETIJOVÁ L et al. Chemometric evaluation of hypericin and related phytochemicals in 17 in vitro cultured Hypericum species, hairy root cultures and hairy root-derived transgenic plants. J Pharm Pharmacol. 2019; 71: 46-57.

8. SINGLETON VL, ORTHOFER R, LAMUELARAVENTÓS RM. [14] Analysis of total phenols and other oxidation substrates and antioxidants by means of folinciocalteu reagent, in: Methods in Enzymology. Methods Enzymol. 1999; 299: 152-178.

9. ARVOUET-GRAND A, VENNAT B, POURRAT A, LEGRET P. Standardization of a propolis extract and identification of the main constituents. J Pharm Belg. 1994; 49: 462-468.

10. SHRIVASTAVA A, GUPTA VB. Methods for the determination of limit of detection and limit of quantitation of the analytical methods. Chron Young Sci. 2011; 2: 21.

11. BLOIS MS. Antioxidant determinations by the use of a stable free radical. Nature. 1958; 181: 1199-1200.

12. RE R, PELLEGRINI N, PROTEGGENTE A, PANNALA A et al. Antioxidant activity applying an improved ABTS radical cation decolorization assay. Free Radical Bio Med. 1999; 26: 1231-1237.

13. AYAN AK, CIRAK C. In vitro Multiplication of Hypericum heterophyllum, an Endemic Turkish species. American Journal of Plant Physiology. 2006; 1(1): 76-81.

14. KHAN SA, VERMA P, ARBAT A, GAİKWAD S et al. Development of enhanced hypericin yielding transgenic plants and somaclones: High throughput direct organogenesis from leaf and callus explants of Hypericum perforatum. Ind Crop Prod. 2018; 111:544-554.

15. SOOD H, SHITIZ K, SHARMA N. Rapid method for in vitro multiplication of Hypericin rich shoots of Hypericum perforatum. J Plant Sci. 2015; 3: 279-284.

16. BĂCILĂ I, COSTE A, HALMAGYI A, DELIU C. Micropropagation of Hypericum maculatum Cranz an important medicinal plant. Rom Biotechnol Lett. 2010; 5(1): 86-91.

17. CUI XH, CHAKRABARTY D, LEE EJ, PAEK KY. Production of adventitious roots and secondary metabolites by Hypericum perforatum L. in a bioreactor. Bioresour Technol. 2010; 101: 4708-4716.

18. KUMAR V, MOYO M, GRUZ J, ŚUBRTOVÁ M et al. Phenolic acid profiles and antioxidant potential of Pelargonium sidoides callus cultures. Ind Crop Prod. 2015; 77: 402-408

19. DANOVA K, NIKOLOVA-DAMIANOVA B, DENEV $\mathrm{R}$, DIMITROV D. Influence of vitamins on polyphenolic content, morphological development, and stress response in shoot cultures of Hypericum spp. PCTOC. 2012; 110: 383-393.

20. CIRIMINNA R, FIDALGO A, MENEGUZZO F, PARRINO FE et al. Vanillin: The Case for Greener Production Driven by Sustainability Megatrend. ChemistryOpen. 2019; 201900083.

21. DELISI R, CIRIMINNA R, PARRINO F, PALMISANO $\mathrm{L}$ et al. One-Pot, clean synthesis of vanillic acid from ferulic acid. ChemistrySelect. 2016; 1: 626-629.

22. SEKEROGLU N, URLU E, KULAK M, GEZICI S et al. Variation in total polyphenolic contents, DNA protective potential and antioxidant capacity from aqueous and ethanol extracts in different plant parts of Hypericum perforatum L. Indian J Pharm Educ. 2017; 51: 1-73. 